\title{
Editorial
}

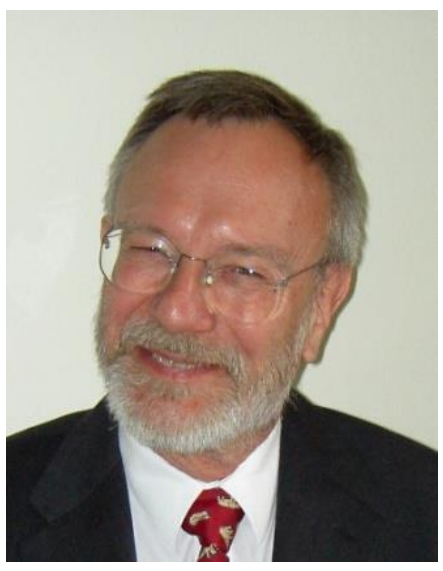

\section{Is Climate Change Essentially Unavoidable?}

\author{
Prof. emeritus, Dr. Jens Christian Tjell
}

Technical University of Denmark

DK-2800 kgs. Lyngby, Denmark

E-mail:jctj@env.dtu.dk

Remembering the recent nearly unsuccessful Conference of the Parties (COP 19) under the Intergovernmental Panel on Climate Change (IPCC) in Warsaw and the concurring November natural disaster in the Philippines? The COP 19 ended in virtually nothing concrete, indicating that the governmental representatives before and during the meeting could not reach consensus on the seriousness of the global warming and its consequences. Some still think it may be too hasty and unjustified to link the looming global warming to the strength of the hurricanes in the tropics as being one of the most probable negative impacts. And even less to act on the threats.

However, the first strict physics tale says that the global temperature has to rise with the atmospheric concentrations of green house gases, somewhat augmented by the cooling set about by atmospheric particles reflecting the sun's energy, and the large volume of cold water in the deep oceans. The second tale of the strict physics is that the evaporation from the oceans will increase (exponentially) with the surface water temperature and the emerging hurricanes will be fed by warm air with ever increasing water vapour content and thus be increasing violent. For scientists these short stories are essentially credible and correct. The consequences of the global warming will gradually be visible to us.

Fortunately, the climate change sceptics mostly basing their belief on political ideology are generally dying out, although some hardliners still survive. But the real hard question is how to avert the global warming or to live with it, or both. The first option is pretty difficult to achieve entirely as the global demand for cheap energy is tremendous and picking up after the global economic crisis with a large GHG emission as a sure consequence. The second option may be attractive to nations in the temperate zones as the expected global $2-6{ }^{0} \mathrm{C}$ increase may only be pleasant, although some low lying areas will be flooded. For less fortunate nations in the tropics, the consequences are disastrous with high average temperatures and flooded coastal regions, and probably droughts lowering food production. It is difficult to overlook the resulting enormous population migrating to neighbouring safer regions and countries, which likely are most unwilling to take in that many climate refugees. Just imagine the terrible scenario when maybe hundred million refugees from overcrowded and very low lying Bangladesh gradually force their way into bordering India, which is equally highly populated. It is most unlikely that it will be a peaceful event. The human suffering and the expenses will be horrendous. The sad thing is that the most affected populations are only marginally responsible for the global warming.

Science has spoken repeatedly through the IPCC reports about the possible scenarios right from "Business as Usual" to the most aggressive and rigorous cutting back on GHG emissions. The next IPCC summary report is due in October 2014. Already now, the summary of the recent scientific basis for the assessments is available as a summary for Policymakers, as Climate Change 2013: The Physical Science Basis, at: http://www.ipcc.ch/. The clear message is that global warming and climate change is ongoing and that the "Business as Usual" is ongoing. 
The lesson is that the politicians are not ready or responsive yet to face the challenges. Can we expect their timely and firmer grip to cope with the future climate changes and the consequences? Probably not, although economists, scientists, inventors, industries and many others are positively pointing to the many possible ways to slow down the global warming, and/or to prevent, mitigate and remediate the destructive consequences. It is equally clear that the slower the response to the challenges, the more expensive it will be for the global community to cope in the future.

In Europe we can influence the future via the EU Commission, our national governments, counties and communes, depending on our national organisation. Our direct activities may be organised in the civic societies as NGOs and other private national and international organisations, and right down to the education and behaviour we give our children.

Despite what many EU citizens believe, the EU commission is apparently quite progressive in its efforts to change the attitudes of national governments towards willingness to act. The plan is to allocate $20 \%$ of the EU budget to climate, and to promote long-term political thinking in the member countries. But as we also know the present Commission ends its term in 2014. We can only hope that the present positive attitudes will carry on.

However, the major force should, and can be the public pressure. Our politicians at all levels are sensitive to the public opinion. Apparently, there are wide differences in attitudes between our national governments as well as between segments of the populations depending on the advantages and disadvantages felt if global warming and climate change should be counteracted. Therefore, a good part of the necessary changes in public attitudes will be to develop methods, technology and policies so that a majority of the population can see their advantages. Especially important is to promote the already well described methods e.g. green technology, energy conservation, renewable energy production, circular economy and the zero-waste society, less wasteful lifestyles (ex: less meat-more plants), promotion of public transport, preventive health policies and much more. If a mix of these methods is adopted and implemented the major advantage is an increase in job opportunities helping individuals as well as national budgets, while we can expect slowing the global warming.

The real challenge is to devise the correct (monetary) value of services and materials, so that human beneficial behaviour is promoted while wasteful behaviour is minimised. Properly designed taxing and financial support as incentives to promote all the beneficial initiatives is often mentioned as the most effective, helped along with public pressure, voiced opinion and initiatives for changes.

Is it possible just marginally to be optimistic about the future climate initiatives in our countries? 